\title{
On the definition of distribution equilibrium potentials in the distribution systems with simple salts
}

\begin{abstract}
A deviation in the definition of distribution equilibrium potential between electrochemical and extraction-chemical phenomena was discussed and examined quantitatively.
\end{abstract}

Keywords: distribution equilibrium potential, inner potential, Nernst equation, conditional distribution constant, distribution ratio, distribution of simple salts
Volume 8 Issue 5 - 2019

\section{Yoshihiro Kudo}

Graduate school of science and engineering, Chiba University, Japan

Correspondence: Yoshihiro Kudo, Graduate school of science and engineering, Chiba university, I -33 Yayoi-cho, Inage-ku, Chiba 263-8522, Japan, Tel +80-43-290-2786,

Email iakudo@faculty.chiba-u.jp

Received: August 27, 2019 | Published: September 04, 2019

Abbreviations: Org, organic; Dep, distribution equilibrium potential; ISE, Ion-selective electrode

\section{Introduction}

In electrochemistry and analytical chemistry, the following equations have been employed.,

$$
\begin{gathered}
E=E^{0^{\prime}}-(R T / z F) \ln \left(C_{R} * / C_{O}{ }^{*}\right) \\
E m f=\text { constant }+(0.05916) \log \left[M^{I} X\right]_{t} \text { at } 298 K, \\
\Delta \varphi_{1 / 2}=\Delta \varphi_{M}{ }^{o^{\prime}}+(R T / z F) \ln \left\{\left(1+\xi K_{D}+\beta_{1}{ }^{w} c_{M} *\right) / \xi K_{D} \beta_{1}{ }^{o r g} c_{M} *\right\}, \\
\text { And } \\
E_{j}=A(R T / F) \ln \{\Sigma|z| u C(\alpha) / \Sigma|z| u C(\beta)\}
\end{gathered}
$$

With

$$
A=\{\Sigma(|z| u / z)[C(\beta)-C(\alpha)]\} /\{\Sigma|z| u[C(\beta)-C(\alpha)]\}
$$

These Equations 1,2,3, \& 4 shown so-called the Nernst equation ${ }^{1}$ for the electrode reaction $\mathrm{O}+\mathrm{ze}^{-} \rightarrow \mathrm{R}$, a calibration curve based on potentiometric measurements with $\mathrm{ISE}^{1}$, a polarographic half-wave potential for a facilitated ion transfer across liquid/liquid interfaces, ${ }^{2}$ and the Henderson equation ${ }^{1}$ for a liquid junction potential, respectively. The concentrations $\mathrm{C}_{\mathrm{R}}{ }^{*}, \mathrm{C}_{\mathrm{O}}{ }^{*},\left[\mathrm{M}^{\mathrm{I}} \mathrm{X}\right]_{\mathrm{t}}, \mathrm{c}_{\mathrm{M}}{ }^{*}, \mathrm{C}(\beta)$, and $\mathrm{C} \alpha$ in the equations denote bulk total concentrations of their ions (and salts). That is, they do not reflect net concentrations of individual ions (or ion pairs) in the bulk phase. In this opinion, we pointed a deviation in definition between the potentials ${ }^{1,2}$ in Equation 1-4 and DEP $^{3}$ obtained experimentally from the simple MX distribution systems and sub-quantitatively examined its correction procedure.

\section{Discussion}

For example, considering the mass balances in the $\mathrm{MCl}$ aqueous solutions relevant to the above equations, the concentrations in Equation 2 to 4 must be more-precisely expressed by using the equilibrium concentrations as

$$
\begin{aligned}
{[\mathrm{MCl}]_{t}=\left[\mathrm{M}^{+}\right]+[\mathrm{MCl}]=\left[\mathrm{Cl}^{-}\right]+[\mathrm{MCl}], } \\
\mathrm{c}_{\mathrm{M}^{*}}=\left[\mathrm{M}^{+}\right]+[\mathrm{MCl}]
\end{aligned}
$$

And

$$
C(\alpha)=\left[M^{+}\right](\alpha)+[M C l](\alpha)
$$

When dilute solutions are used for their experiments, the [MCl] and $[\mathrm{MCl}](\alpha)$ (the concentration for the $\alpha$ phase at equilibrium) terms can be generally neglected. The same expression as those in Equation (2A) to (4A) essentially holds for $\mathrm{C}_{\mathrm{R}}{ }^{*}$ and $\mathrm{C}_{\mathrm{O}}{ }^{*}$ in Equation 1. So, the $\mathrm{C}_{\mathrm{R}}{ }^{*}, \mathrm{C}_{\mathrm{O}}{ }^{*},\left[\mathrm{M}^{\mathrm{T} X}\right]_{\mathrm{t}}, C_{\mathrm{M}}{ }^{*}$, and $\mathrm{C}(\alpha)$ terms do not necessarily equivalent to the ionic strength $(I)$ for the phase. Accordingly, the $\mathrm{E}$, emf, $\Delta \varphi_{1 / 2}$, and $E_{j}$ values are defined as fundamentally the difference between inner potentials $(\varphi)$ for the two phases, such as the phases with liquid/ solid $^{1}$ and liquid/liquid interfaces. ${ }^{1,2}$ Namely, Equation 1 to 4 describe the differences $\Delta \varphi$ in overall energy between the two phases.

On the other hand, in extraction and distribution systems, a conditional distribution constant $\left(K_{\mathrm{D}} \mathrm{p}_{\mathrm{i}}\right)$ of a single ion $(i)$ between the two bulk phases has been defined as the ratio of the concentrations (or activities) of the individual i with DEP at equilibrium ${ }^{1,3,4}$ and a standard distribution constant $\left(K_{\mathrm{D}}{ }^{{ }^{\mathrm{S}}}{ }_{\mathrm{i}}\right)$ at $\mathrm{DEP}=0 \mathrm{~V} \cdot{ }^{3,4}$ It is

$$
K_{D},_{i}=[i]_{\text {org }} /[i]=K_{D},{ }_{i}^{S} \exp \left\{\left(z_{i} F / R T\right) \operatorname{dep}\right\}
$$

And this modified form is

$$
d e p=\left(R T / z_{i} F\right)\left(\ln K_{D, i}-\ln K_{D}{ }_{i}{ }^{S}\right)
$$

Here, $z_{i}$ denotes the formal charge $z$ with the sign of the ion $i$. In Equation (5) or (5A), the $\mathrm{K}_{\mathrm{D}}$ ' $_{i}$ value contains only the amount of an ionic component, such as $\mathrm{i}=\mathrm{M}^{+}$or $\mathrm{Cl}^{-}$. These facts indicate that with the difference $\Delta \varphi$ of only the individual $\mathrm{M}^{+}$or $\mathrm{Cl}^{-}$is expressed Equation (5A), while Equation 1 to 4 are done with the $\Delta \varphi$ of the mixture of $\mathrm{M}^{+}, \mathrm{Cl}^{-}$, and $\mathrm{MCl}$. This means that the electrochemical 
definition for $\mathrm{E}$, emf, $\Delta \varphi_{1 / 2}$, and $\mathrm{E}_{\mathrm{j}}$, can slightly deviate from the dep definition based on the experimental $\mathrm{K}_{\mathrm{D}, \mathrm{i}}$ values. ${ }^{1,3,4}$ Of course, the energetic states of the phases may influence the $\mathrm{K}_{\mathrm{D}}{ }_{\mathrm{i}}$ determination in the extraction experiments.

By the way, the distribution ratio $(D)$ has been defined as

$$
D=c_{t},_{\text {org }} / c_{t}=\left(\left[M^{+}\right]_{\text {org }}+[M X]_{\text {org }}\right) /\left(\left[M^{+}\right]+[M X]\right)
$$

In the simple MX distribution systems. ${ }^{3,5}$ Here, the symbols $\mathrm{c}$ and $\mathrm{c}_{\mathrm{t} \text { org }}$ denote the total concentrations of the species with $\mathrm{M}(\mathrm{I})$ \{or $\mathrm{X}(-\mathrm{I})\}$ in the water and org phases, respectively.

Equation (6) can be rearranged as $D=$

$$
\left(\left[M^{+}\right]_{o r g} /\left[M^{+}\right]\right) \times\left(1+K_{M X} \operatorname{org}^{-}\left[X^{-}\right]_{\text {org }}\right) /\left(1+K_{M X}\left[X^{-}\right]\right)
$$

With $\mathrm{K}_{\mathrm{MX} . \text { org }}$

$$
=[M X]_{\text {org }} /\left[M^{+}\right]_{\text {org }}\left[X^{-}\right]_{\text {org }} \text { and } K_{M X}=[M X] /\left[M^{+}\right]\left[X^{-}\right] \cdot 3,5
$$

Using Equation (5) with the charge balance relations

$$
\left[\mathrm{M}^{+}\right]=\left[\mathrm{X}^{-}\right]=I \text { and }\left[\mathrm{M}^{+}\right]_{\text {org }}=\left[\mathrm{X}^{-}\right]_{\text {org }}\left(=I_{\text {org }}\right),
$$

Equation (6A) also becomes

$$
D=\left(1+K_{M X} \text { org } K_{D},{ }_{X} I\right) /\left(1+K_{M X} I\right) \times K_{D, M}=r K_{D, M}=r K_{D, X}
$$

With $\quad r=\left(1+K_{M X, \text { org }} K_{D, X} I\right) /\left(1+K_{M X} I\right)$

Moreover, assuming that $D^{S}=r^{\prime} K_{D, i}{ }^{S}$ at $\mathrm{DEP}=0$, the following equation can be derived from Equations (5) \& (6B):

$$
D=D^{S} \exp \left\{\left(z_{i} F / R T\right) \operatorname{dep}\right\}=c_{t} \text {, org } / c_{t}
$$

This equation is very similar to the above electrochemical expression, ${ }^{1,2}$ because the $c_{t}$ and $c_{t^{\prime} \text { org }}$ terms are equivalent with the expression of $\mathrm{C}_{\mathrm{R}}{ }^{*}, \mathrm{C}_{\mathrm{O}}{ }^{*},\left[\mathrm{M}^{\mathrm{I} X}\right]_{\mathrm{t}}, \mathrm{c}_{\mathrm{M}}{ }^{*}$, and $\mathrm{C}(\alpha)$. That is, the dep values calculated from D, based on Equation (7), approach to the definition corresponding to $\mathrm{E}$, emf, $\Delta \varphi_{1 / 2}$, and $\mathrm{E}_{\mathrm{j}}$. Also, the use of $\mathrm{D}$ is not in conflict with the above electrochemical definitions.

Table 1 summarizes some experimental $\mathrm{K}_{\mathrm{D}, \pm}$ and $\mathrm{D}$ values ${ }^{3}$ in the MX distribution into several diluents, where the relation $\left(K_{D, M} K_{D, X}\right)^{1 / 2}=K_{D, \pm}$ holds. ${ }^{3,4}$ The plot of $\log K_{\mathrm{D}, \pm}$ versus $\log D$ listed in Table 1 yielded $\log K_{D, \pm}=(0.98 \pm 0.04) \log D-(0.10 \pm 0.13)$ at the correlation coefficient of 0.996 . This regression line shows that the $\log \mathrm{K}_{\mathrm{D} \pm}$ values are proportional to the $\log \mathrm{D}$ ones, namely $\log K_{\mathrm{D}_{ \pm}}=\log$ $D-\log r$ ssee Equation (6B) $\}$. In other words, this fact indicates that $\mathrm{K}_{\mathrm{D}, \pm}$ is a function of $\mathrm{D}$ and $\mathrm{r}$. When the $\mathrm{r}$ value is approximately equal to unity, we can immediately obtain $\mathrm{D} \& \mathrm{~K}_{\mathrm{D}+}$ which equals $\mathrm{K}_{\mathrm{D}, \mathrm{M}}$ and $\mathrm{K}_{\mathrm{D}, \mathrm{X}}$. The intercept $(=\log \mathrm{r} \approx 0.1)$ of the regression line shows the possibility that the evaluated $\mathrm{r}$ values equal unity within the calculation error $(\geq 0.1)$.

Table I Experimental $\log K_{\mathrm{D} . \pm}$ and $\log D$ values for the MX distribution into several diluents at $298 \mathrm{~K}$

\begin{tabular}{lllll}
\hline Diluent & $\mathrm{MX}^{\mathrm{a}}$ & $\log K_{\mathrm{D}, \pm} \mathrm{b}$ & $\log \mathrm{D}$ & Ref. \\
\hline Nitrobenzene & $\mathrm{NaMnO}_{4}$ & -3.17 & -3.17 & 3 \\
& $\mathrm{NaPic}$ & -2.62 & -2.61 & \\
& $\left(\mathrm{CH}_{3}\right)_{4} \mathrm{NPic}$ & 0.053 & 0.07 & \\
I,2-Dichloroethane & $\mathrm{NaMnO}_{4}$ & -4.7, & -4.72 & 3 \\
& $\mathrm{NaPic}$ & -3.55 & -3.58 & \\
& $\left(\mathrm{C}_{2} \mathrm{H}_{5}\right)_{4} \mathrm{NPic}$ & -1.011 & -0.90 & \\
o-Dichlorobenzene & $\mathrm{LiPic}$ & $-5.3_{0} \pm 0.3_{9}$ & $-5.5_{5} \pm 0.1_{0}$ & This \\
& $\mathrm{NaPic}$ & $-4.8_{2} \pm 0.4_{6}$ & $-4.53 \pm 0.04$ & \\
& $\mathrm{KPic}$ & $-3.9_{2} \pm 0.3_{9}$ & $-3.6_{1} \pm 0 . \mathrm{I}_{3}$ & \\
\hline
\end{tabular}

a MPic: picrate. ${ }^{\mathrm{b}}$ The relation $\mathrm{K}_{\mathrm{D}, \pm}=\mathrm{K}_{\mathrm{D}, \mathrm{M}}=\mathrm{K}_{\mathrm{D}, \mathrm{X}}$ holds in the present distribution systems. ${ }^{3}$

\section{Conclusion}

Consequently, the DEP in Equations (5) and (5A) satisfies the electrochemical definition in the case of $r \approx 1$. At the same time, the definition for $C_{\mathrm{R}}{ }^{*},\left[\mathrm{M}^{\mathrm{I} X}\right]_{t}$, and $C(\alpha)$ is reflected into indirectly the $K_{\mathrm{D}+}$ values through the $D$ ones. A similar discussion will be also needed for the more-complicated extraction systems $\mathrm{s}^{4,6}$ with various extracting reagents.

\section{Acknowledgments}

None

\section{Conflicts of interest}

The author declares that there are no conflicts of interest.

\section{References}

1. Bard AJ, Faulkner LR. Electrochemical Methods: Fundamentals and Applications. 2nd ed. John Wiley \& Sons, Inc., New York NY. 2001;52, $72,75, \& 253 \mathrm{p}$.

2. Matsuda H, Yamada Y, Kanamori K, et al. On the facilitation effects of neutral macrocyclic ligands on the ion transfer across the interface between aqueous and organic solutions. I. Theoretical equation of ion-transferpolarographic current-potential curves and its experimental verification. Bulletin of the Chemical Society of Japan. 1991;64(5):1497-1508.

3. Kudo Y, Harashima K, Hiyoshi K, et al. Extraction of some univalent salts into 1,2-dichloroethane and nitrobenzene: Analysis of overall extraction equilibrium based on elucidating ion-pair formation and evaluation of standard potentials for ion transfer at the interface between their diluents and water. Analytical Sciences. 2011;27(9):913-919. 
4. Kudo Y, Takeuchi T. On the interfacial potential differences for the extraction of alkaline-earth metal picrates by 18 -crown- 6 ether derivatives into nitrobenzene. Journal of Thermodynamics \& Catalysis. 2014;5(2):6.

5. Rais J. Individual extraction constants of univalent ions in the system waternitrobenzene. Collection of Czechoslovak Chemical Communications. 1971;36(9):3253-3262.
6. Kudo Y, Amano T, Ikeda S. Determination of distribution equilibriumpotential difference based on extraction with several crown ethers by nitrobenzene, 1,2-dichloroethane and dichloromethane. International Journal of Chemistry. 2017;9(4):110-123. 